\title{
Representações e identidades femininas: práticas de turismo criativo no Sarau Imperial
}

Representations and feminine identities: creative tourism practices in the Imperial Sarau

Frederico Ferreira de Oliveira

Professor do Curso de Turismo do Instituto Federal do Rio de Janeiro - IFRJ, Rio de Janeiro/RJ, Brasil

E-mail: turofredfo@uol.com.br

Jarlene Rodrigues Reis

Professora do Curso de Turismo do Instituto Federal do Rio de Janeiro - IFRJ, Rio de Janeiro/RJ, Brasil

E-mail: jarlenerodrigues@yahoo.com.br 


\section{RESUMO}

Promovido pelo Museu Imperial de Petrópolis, o Sarau Imperial é a encenação de uma reunião social entre a Princesa Isabel e algumas de suas amigas. A dramatização, cujo elenco é formado somente por mulheres, reúne performances musicais, declamações de poemas, leituras de trechos de jornais do século XIX e interações entre o elenco e a plateia. Neste artigo analisamos as práticas de turismo criativo empregadas na produção do Sarau Imperial, investigando sua relação com a representação de identidades femininas durante a encenação. Leituras de Richards, Raymond, Wilson e Cloke formam o quadro teórico turismo criativo e autoras como Butler, Octobre, Scott e Rago, do campo de estudos de gênero e identidades femininas, completam o referencial. Foi realizada observação participante do Sarau durante três apresentações em novembro de 2016, além de registros audiovisuais e consultas aos produtores da encenação. Observou-se que o Sarau Imperial se constitui como profícua plataforma de reflexões críticas sobre a identidade feminina a partir da interação entre elenco e público, que participa ativamente da dramatização e é convidado a reinventá-la a cada nova sessão.

Palavras-chave: Sarau Imperial. Petrópolis. Turismo Criativo. Representações Femininas.

\section{ABSTRACT}

Promoted by the Imperial Museum of Petropolis, the Imperial Sarau is the staging of a social gathering between Princess Isabel and some of her friends. The drama, whose cast consists only of women, brings together musical performances, recitals of poems, readings from nineteenth-century newspaper sections and interactions between the cast and the audience. In this article we analyze the creative tourism practices employed in the production of the Imperial Sarau, investigating its relation with the women's representations of feminine during the staging. Richards, Raymond, Wilson, and Cloke form the theoretical framework of creative tourism, and authors such as Butler, Octobre, Scott and Rago, from the field of gender studies and feminine identities, complete the framework. Participant observation of the Sarau was realized during three presentations in November 2016, besides audiovisual registries and consultations to the producers of the staging. It was observed that the Imperial Sarau constitutes a profitable platform of critical reflections on the feminine identity from the interaction between cast and audience, who participates actively in the dramatization and is invited to reinvent it each new session.

Keywords: Imperial Sarau. Petropolis. Creative Tourism. Women's Representations. 


\section{INTRODUÇÃO}

As manifestações culturais contemporâneas se apresentam como plataformas em que se articulam imaginários e sentidos capazes de promover reflexões, questionamentos e transgressões em relação aos padrões socioculturais. Múltiplas identidades e memórias são representadas em performances que cada vez mais oferecem possibilidades de interação e produção coletiva, transformando roteiros em elementos flexíveis a serem constantemente reinventados e ressignificados.

Considerando a existência de públicos ávidos por narrativas singulares, as práticas de turismo criativo se configuram como novas formas de apropriação de atividades e atrativos culturais em que os espectadores exercem papel ativo e de coprodução. Nessa perspectiva, a cultura e a história de uma localidade servem como ponto de partida para que os visitantes pratiquem seu potencial criativo em constante interação com os elementos que os atraem (Richards, 2010).

Além das principais atrações do maior museu brasileiro sobre o Segundo Reinado ${ }^{1}$, o Museu Imperial, localizado na cidade de Petrópolis, no estado do Rio de Janeiro, oferece a seus visitantes o Sarau Imperial. A encenação, que se configura como uma dramatização criada a partir de elementos significativos desse período histórico, apresenta à plateia a oportunidade de conhecer aspectos socioculturais da Corte Imperial Brasileira ao mesmo tempo em que participa como "convidada" da anfitriã, a Princesa Isabel. O Sarau conta com elenco integralmente feminino e promove momentos de interação com a platéia, convidada a participar em performances musicais, poéticas, bem como na expressão de opiniões sobre assuntos colocados em pauta durante a apresentação.

Temáticas e formas de comportamento típicas do período histórico representado recriam a atmosfera da época, servindo como oportunidades para o estranhamento e a comparação com os padrões culturais atuais, provocando questionamentos sobre o imaginário e a identidade feminina entre as personagens e o público do Sarau Imperial.

Nosso objetivo consiste em investigar as representações e os imaginários femininos reproduzidos durante a encenação do Sarau Imperial a partir das práticas de turismo criativo nele encontradas. Partindo de leituras sobre turismo cultural e criativo (Richards, 2010), gênero e representações femininas (Butler, 1999; Rago, 1995; 1998), buscamos compreender

\footnotetext{
${ }^{1}$ Período histórico no qual o Brasil foi governado pelo Imperador D. Pedro II, tendo início em 1840 e término em 1889, com duração total de 49 anos. O Museu Imperial possui documentos e conjuntos documentais e bibliográficos que fazem parte do patrimônio da humanidade, declarados pela Organização das Nações Unidas para a Educação, a Ciência e a Cultura (UNESCO), o que o torna o mais importante e representativo museu brasileiro sobre os aspectos socioculturais e econômicos do Segundo Império.
} 
de que forma se articulam no Sarau os aspectos da encenação aberta e participativa, bem como os elementos que denotam identidades de gênero, com foco na representação do feminino.

Em termos metodológicos, após a revisão de literatura foi realizada observação participante de três encenações do Sarau Imperial durante o mês de novembro de 2016, além da coleta de registros audiovisuais e de relatos de membros da produção da encenação. Tais procedimentos tiveram como intuito acompanhar diversos momentos do Sarau, observando aspectos da produção e da interação entre o público e o elenco.

A pesquisa possibilitou observar discursos e representações de um importante atrativo turístico e cultural da cidade de Petrópolis, contribuindo para que se conheçam as possibilidades de desenvolvimento de novas práticas turísticas criativas e experiências numa cidade já consolidada no cenário turístico brasileiro.

\section{O TURISMO CRIATIVO COMO APORTE PARA NOVAS FORMAS DE CONSUMO DA CULTURA LOCAL}

Os deslocamentos provocados no intuito de conhecer/consumir certas destinações ao redor do mundo possibilitam que o turismo venha se consolidando como uma importante prática de lazer (descanso e diversão) aliada a outras motivações, tais como trabalho, aprendizagem ou aperfeiçoamento profissional, desde o final do século XIX até os dias atuais (Funari \& Pinsky, 2011).

Entre a Antiguidade Clássica e a Idade Moderna, o interesse em conhecer novas culturas foi o objetivo central que caracterizou os deslocamentos (Yasohima \& Oliveira, 2002), no intuito da busca pelo desconhecido sob a ótica do cotidiano, dos hábitos e costumes pessoais, a fim de encontrar novas formas de sociedade, conhecimento e cultura.

No decurso do tempo a cultura vai motivando os deslocamentos de viajantes para a apreciação e o conhecimento de outros elementos culturais, até que na Idade Moderna, por meio do movimento renascentista, as viagens são incentivadas para estudos e experiências, tendo como principais praticantes professores, artistas e intelectuais (Yasohima \& Oliveira, 2002; Molina, 2003).

Essa prática se torna reconhecida até os dias de hoje por vários estudiosos quando se configura o Grand Tour - denominação conferida a viagens que possuíam o objetivo de dar ao homem solteiro a condição de se preparar para tornar-se membro das classes poderosas durante os séculos XVII e XVIII: a viagem incluía o percurso pelos principais cidades europeias e centros de estudos no intuito de desenvolver nesses praticantes a educação para 
que se tornassem futuros estadistas profissionais e embaixadores (Yasohima \& Oliveira, 2002; Molina, 2003).

Há de se destacar que às mulheres das famílias abastadas não era permitida a prática das viagens características do Grand Tour, visto que os deslocamentos, o contato com diferentes pessoas e lugares poderiam representar grandes ameaças para sua virgindade (Yasohima \& Oliveira, 2002). Dessa forma, elas permaneciam em suas cidades de origem à espera dos doutos viajantes como futuros pretendentes.

O contexto das viagens vai se alterando ao longo dos anos, como assinalado por Rejowski et al (2002), sendo possível perceber que nos diferentes processos de transformação da atividade turística os elementos culturais são sempre aqueles que despertam o interesse dos viajantes: seja pela busca do lugar e das construções diferentes e/ou exóticas, seja pela forma de comportamento de certa população/região/país.

Richards (2010) descreve que o turismo cultural representa ainda para os tempos atuais importante forma de consumo das destinações que possuem a cultura, o patrimônio cultural, museus e outros espaços destinados à cultura como elementos âncora para a atração de turistas e visitantes.

Há de se destacar que o turismo cultural vai para muito além desses elementos âncoras ditos por Richards (2010) e que são problematizados por Funari e Pinsky (2011, p. 9), pois ao se considerar somente o patrimônio cultural como “[...] aquele que se volta para certos tipos de atividades mais propriamente 'culturais', tais como as visitas a museus, a cidades históricas ou a roteiros temáticos", pode-se deixar de lado aquilo que de fato é o patrimônio cultural de uma destinação: a cultura que está permeada nas pessoas, na sua forma de comportamento, que são elementos advindos da relação social com seu passado e sua memória (Le Goff, 1990).

Se existe esta relação entre turismo e cultura, é preciso considerar que muitas destinações passaram a ofertar seu patrimônio cultural, sua história e sua memória como objetos de consumo para turistas e visitantes, significando nos dizeres de Richards e Wilson (2006; 2007), práticas para as novas narrativas e temáticas baseadas no placemaking.

Com a grande oferta de destinos turísticos culturais é preciso que seja (re)pensada tanto a oferta dos atrativos quanto a narrativa a ser consumida pelos turistas e visitantes (Richards \& Wilson; 2006), buscando a partir da matriz cultural ofertada a regeneração da cultura urbana e rural, bem como as tradições locais em direção à oferta de elementos/produtos simbólicos. 
Essa oferta da cultura, história e tradições locais como novos elementos simbólicos ultrapassa a visão patrimonialista do bem imóvel como categoria de atrativo a ser consumida, pois Richards e Wilson (2006; 2007) e Richards (2010) se aproximam de uma nova visão daquilo que é cultura, a qual é proposta por Geertz (1989, p. 52):

[...] cultura é o padrão, historicamente transmitido, de significados incorporados em símbolos, um sistema de concepções herdadas, expressas em formas simbólicas, por meio das quais os homens se comunicam, perpetuam e desenvolvem seu conhecimento e suas atitudes acerca da vida.

A visão de cultura de Geertz (1989) se encontra refletida naquilo que novos turistas, pós-turistas (Molina, 2003), estão em busca: de consumirem produtos e serviços turísticos que possam ser capazes de gerar experiências novas, não sendo mais apenas apreciadores passivos de objetos/locais estáticos; os novos turistas buscam por consumir aquilo que é autêntico, que possui laços com a tradição local, a cultura e a memória de forma mais próxima e ativa (Richards \& Wilson, 2006).

O turismo criativo emerge nessa conjuntura de mudanças e inquietações, trazendo à tona e para a prática posturas que passam a olhar a cultura, as tradições locais, a história e a memória como elementos capazes de serem ainda melhores e mais bem aproveitados pela atividade turística (Richards, 2010).

Os primeiros conceitos voltados para o turismo criativo são formulados por Richards e Raymond (2000) apregoando que a atividade turística deve ofertar aos visitantes a oportunidade de desenvolverem seu potencial criativo por meio da participação ativa em atividades como cursos e experiências de aprendizagem baseadas na oferta de produtos e serviços que se baseiem nas características da cultura e história da destinação turística.

Richards (2010), ao revisitar os pensamentos de Richards e Raymond (2000) além de (Richards \& Wilson, 2006), aponta que o turismo criativo traz importantes implicações para as destinações que passem a adotar a criatividade enquanto elemento/instrumento no planejamento e execução de novos produtos e serviços turísticos: o turista passa a dispor de ferramentas para desenvolver seu próprio potencial criativo, além de levar consigo as experiências e lembranças da visitação; o turista está ativamente envolvido no processo criativo, e esse envolvimento cria o potencial para o intercâmbio genuíno e o envolvimento com a população e a cultura local. A criatividade pode acontecer em qualquer lugar, mas o importante é vincular o processo ao destino para ancorá-lo na cultura, na criatividade e na identidade local, requerendo o uso de práticas criativas não apenas por parte do turista, mas também na perspectiva do destino. 
Avançando nesta compreensão é que, segundo a própria Unesco (2013), o turismo criativo é aquele em que o turista/visitante deve ter interação educativa, emocional, social e participativa com o local, sua cultura e os moradores locais, devendo assim se sentir como cidadão do espaço visitado.

A esta maneira o uso da criatividade por meio do turismo criativo permite que a atividade turística possa expandir a ideia do olhar do turista sob a destinação visitada (Urry, 1996). O entendimento do turismo criativo se faz a partir de um novo comportamento daquele que o pratica: assumindo o papel de coprodutor criativo; consumidor de suas próprias experiências; possui papel ativo na visitação/vivência do local/atração; interação com a comunidade receptora; informação, aprendizagem e valorização da história e da cultura local (Richards \& Wilson, 2006).

Cloke (2007) corrobora os entendimentos de Richards e Wilson (2006), ao afirmar que o turista criativo passa a determinar seu próprio olhar e criar as narrativas de viagens a partir de seu ponto de vista e não mais com o olhar passivo, o de apenas contemplar e absorver o que lhe é passado de forma homogeneizada, ou como explanado por Richards e Wilson (2007) na contraposição da 'McGugenheim', isto é, espaços culturais reproduzidos para gerar as mesmas experiências culturais no turismo.

Contudo Richards e Wilson (2007) são categóricos ao afirmarem que o turismo criativo não deve ser visto sob a pseudo-ótica da panacéia diante à atividade turística já praticada pelo mercado - trata-se apenas de inserir novas discussões sobre como praticar o turismo cultural de forma mais simétrica com a comunidade local e evitar os conflitos socioculturais gerados no espaço geográfico. Nessa perspectiva, faz-se pertinente refletir sobre a forma como são reproduzidos aspectos culturais e identidades locais no contexto das práticas de turismo criativo.

\section{IDENTIDADES E REPRESENTAÇÕES DO FEMININO}

As discussões teóricas sobre o papel da mulher na sociedade ganharam força a partir dos movimentos feministas surgidos nos Estados Unidos na segunda metade do século XX. Estudos com heranças marxistas passaram a reconstruir e questionar identidades, imaginários e papeis sociais atribuídos às mulheres em diversos contextos históricos e sociais, culminando nos "estudos de gênero" iniciados entre as décadas de 1980 e 1990 (Rago, 1998).

Uma das pioneiras nos estudos sobre gênero no Brasil, Rago (1995) ressalta a preocupação, entre os pesquisadores da área, por descontruir a noção a-histórica, abstrata, 
universal e biologicamente determinada de "mulher", a fim de se compreenderem as mulheres na diversidade de contextos históricos em que se encontram.

A busca por uma compreensão não determinista e historicamente situada da condição feminina encontra ecos em pesquisadoras como Joan Scott (1986) e Judith Butler (1999), que propõem o conceito de "gênero" como forma de ampliar o entendimento dos diferentes papeis construídos e reproduzidos socialmente para mulheres e homens, enfatizando o conjunto de relações envolvidas entre os sujeitos sociais, inclusive as relações políticas e de poder.

A palavra "gênero", dessa forma, apresenta-se como uma rejeição ao determinismo biológico de termos como "sexo" e "diferenças sexuais", enfatizando o sistema relacional que "pode incluir o sexo, mas que não é diretamente determinado pelo sexo nem determina diretamente a sexualidade"2 (Scott, 1986, p. 1057, tradução nossa). Para a autora, as categorias "homem" e "mulher" são construções subjetivas e não inerentes ao sujeito. Entendido como reprodução discursiva a partir de diferenças percebidas entre os sexos, o gênero se constitui como forma de significação de relações de poder. Nessa perspectiva é fundamental que se descubram as origens da repressão que leva à permanência da representação binária dos gêneros, a partir do conhecimento mais amplo do contexto político em que se desenvolvem as relações sociais (Scott, 1986).

Aprofundando a reflexão sobre as relações de poder envolvidas na oposição binária entre "homens" e "mulheres", Judith Butler (1999) questiona o modo como a linguagem constrói as categorias de sexo a fim de garantir a manutenção da heterossexualidade compulsória e do falocentrismo como regimes de poder e de discurso. Focando sua análise na condição feminina, a autora ressalta o papel fundamental das formas de representação que, por um lado, atuam para estender visibilidade e legitimidade às mulheres como sujeitos políticos e, por outro, configuram a função normativa de uma linguagem capaz de revelar ou de distorcer o que se toma por verdadeiro a respeito das mulheres. Para Butler (1999), uma grande dificuldade é imposta pelos discursos representacionais restritos segundo os quais haveria uma unidade da categoria "mulheres" como sujeito estável, denotando uma identidade universal comum. Dessa forma, faz-se necessário rever as categorias de identidade de gênero, articulando-as a outros eixos de relações de poder como a etnia e a classe social. A autora propõe a construção variável da identidade como forma de contestação das reificações de gênero e de identidade feminina (Butler, 1999).

\footnotetext{
2 "The use of gender emphasizes an entire system of relationships that may include sex, but is not directly determined by sex or directly determining of sexuality".
} 
Se a ideia de uma "identidade comum" feminina se reproduz pela restrição da representação discursiva, outros elementos de categorização da oposição binária são criados a partir de experiências culturais e de lazer ao longo da infância e da juventude (Octobre, 2011). Nestas fases da vida o indivíduo é submetido a atividades e formas de convivência que reproduzem universos discursivos calcados na oposição entre "masculino" e "feminino", cada um deles fazendo referências ao outro - a exemplo de práticas esportivas, programas culturais e sociais tradicionalmente associados ao universo masculino ou ao feminino. Tais práticas atuam como dispositivos invisíveis de socialização (Buscatto, 2014). Nesse contexto, para Octobre (2011), convém questionar a questão da dominação masculina (elemento sempre presente nas discussões de gênero), em virtude da feminilização crescente da vida cultural. Para a autora, a dominação masculina passou de uma dominação fundada na força à dominação baseada na racionalidade, marca da masculinidade hegemônica contemporânea. Essa nova lógica de dominação, entretanto, penaliza tanto as mulheres quanto os próprios homens (Octobre, 2014).

Para Bourdieu (2012), por sua vez, a dominação masculina está associada a formas de percepção e de apreciação do mundo calcadas nas estruturas históricas da dominação masculina. Ou seja, nossos modos de pensar e refletir sobre a divisão entre os sexos são produtos dessa dominação e reproduzem seus mecanismos na manutenção de visões androcêntricas de mundo, sendo estas consideradas neutras e legitimadas.

Se, apesar das mudanças nas práticas culturais e sexuais as mulheres se encontram sujeitas a uma lógica de relações de poder em que prevalece a dominação masculina (Bozon, 2003), àquelas que almejam posições de destaque em suas interações sociais e profissionais cabe a tarefa de conciliar de forma equilibrada o trabalho, a feminilidade e os sentimentos (Lana \& Leal, 2014). Entretanto, a história permite observar como a presença das mulheres em esferas de poder, hoje considerada natural, nem sempre foi permitida ou tolerada. Sempre houve tensões e conflitos envolvendo a presença feminina em posições e ambientes de liderança e decisão, como retrata a história do Segundo Reinado e da Princesa Isabel do Brasil.

\section{PRINCESA ISABEL DO BRASIL - PODER, POLÍTICA E VIDA SOCIAL NO SEGUNDO IMPÉRIO}

Nascida em 1846, Isabel de Orléans e Bragança foi uma mulher ciente dos papeis que lhe eram impostos pela sociedade patriarcal de sua época. Filha, noiva, esposa, mãe e regente, ela poucas vezes manifestou incômodo com sua situação, a exemplo das mulheres de 
classe alta no período oitocentista, que exerciam passivamente os deveres considerados adequados para elas (Daibert Júnior, 2003).

Entretanto, o envolvimento da Princesa Isabel com a política brasileira durante o Segundo Reinado estremeceu as bases de seu equilíbrio nas funções tradicionalmente femininas. Laureada popularmente como a "Redentora" devido ao seu papel no processo de abolição da escravatura no Brasil, a Princesa é alvo de diferentes interpretações históricas e sociais - por um lado, biógrafos tradicionais a consideram uma princesa com visão política visionária e determinada (Daibert Júnior, 2003 \& Cruz, 2012); por outro ela é vista como uma mulher cuja atuação política se deu de forma acidental e manipulada pelo marido e pelo pai (Barman, 2005).

Mergulhada num universo estritamente masculino, durante o período em que foi herdeira do Trono Imperial D. Isabel exerceu duas funções que, para Cruz (2012) poderiam ser descritas como femininas e masculinas: "as femininas seriam aquelas tidas como 'naturais' às mulheres do século XIX: era filha, esposa e mãe. Dentro da esfera masculina, a Princesa lidou com as funções de Estado, o exercício do poder politico, longe de ser atribuída uma mera influência, mas como protagonista do papel" (Cruz, 2012, p. 43).

O gênero feminino, bem como a grande religiosidade, foram apontados como elementos negativos da Princesa sob o ponto de vista de muitos opositores ao seu envolvimento politico. Cabe lembrar que, para os padrões da época, à mulher caberia somente o espaço privado, familiar e de relações sociais. Dessa forma, a presença de D. Isabel no meio político parecia incomodar principalmente porque a distanciava, em parte, do papel social que se esperava de uma mulher na sua posição (Cruz, 2012).

Entretanto, tendo recebido uma rígida educação formal até as vésperas de seu casamento, aos dezoito anos de idade, a Princesa Isabel possuía vastos conhecimentos que iam desde Literatura à Fotografia, como parte do interesse de seu pai, D. Pedro II, em proporcionar às filhas um nível de instrução semelhante ao que era dedicado aos homens: "A instrução não deve diferir da que se dá aos homens, combinada com a do outro sexo: mas de modo que não sofra a primeira", escreveu o imperador (Filgueiras, 2004, p. 351). Como preceptora da Princesa D. Pedro convidou a Viscondessa e mais tarde Condessa de Barral, D. Luísa Margarida Portugal de Barros.

O alto nível de instrução recebido pela Princesa influenciou a formação de seus gostos e hábitos e, apesar da vida discreta e reclusa durante a juventude, sua vida social contava com a realização de pequenas reuniões no Palácio de São Cristóvão e visitas de filhas dos dignitários da corte e de intelectuais do círculo do imperador. Do seleto grupo faziam 
parte Maria Ribeiro de Avelar, Maria Amanda de Paranaguá (conhecida como "Amandinha") e Adelaide Taunay - as três foram amigas de D. Isabel por toda a vida (Barman, 2005).

Recorrendo às formulações de Bourdieu (2007), a educação da Princesa pode ser entendida como elemento chave para a formação de sua disposição culta, fundamental para a manutenção de sua posição de nobreza na sociedade aristocrática da qual fazia parte. Dessa forma, o conhecimento de literatura, música, teatro e artes plásticas, adquirido ao longo da educação de D. Isabel, fizeram parte do que Bourdieu considera como a formação do "gosto puro", direcionado ao repertório cultural legitimado em um contexto social (Bourdieu, 2007). Mais tarde, o apreço pelas artes e o espírito "festeiro da Princesa iriam se refletir nas recepções semanais que ela oferecia em sua casa em Petrópolis” (Schwarcz, 1998).

Partindo dessas ponderações a respeito das aptidões e da formação cultural da Princesa Isabel, bem como sobre a condição feminina no século XIX, convém investigar de que forma esses elementos estão articulados na apresentação do Sarau Imperial, no Museu Imperial da cidade de Petrópolis, no Rio de Janeiro.

\section{O SARAU IMPERIAL COMO ARENA DE REPRESENTAÇÕES FEMININAS}

Descrito na página virtual do Museu Imperial como uma "dramatização interativa de uma atividade de lazer do século XIX", o Sarau Imperial acontece às quintas, sextas e sábados no Cineteatro do Museu, localizado no Centro Histórico de Petrópolis (Museu Imperial, 2016).

Parte do programa "Tour da Experiência - Caminhos do Brasil Imperial", o Sarau Imperial foi desenvolvido numa parceria que incluiu o SEBRAE, o Instituto Marca Brasil e o empresariado local de Petrópolis, com apoio e parceria do Museu Imperial (Museu Imperial, 2016). Atualmente o Sarau conta com a produção de uma empresa independente de produção cultural, que tem aos poucos realizado a revisão completa do roteiro e do figurino da atração.

A encenação dura cerca de 45 minutos e conta com canções, declamação de poesias e conversas sobre pautas sociais, políticas e culturais do século XIX (Museu Imperial, 2016). Durante a atração, que reproduz uma recepção na casa da Princesa Isabel, ela e as personagens Condessa de Barral, Baronesa de Loreto (Amandinha), Francisca Taunay e Adelaide Taunay interagem entre si e com a plateia, provocando reações inusitadas que possuem como pano de fundo as diferenças entre a cultura da época e os costumes e práticas culturais contemporâneos (Fotografia 1).

Com público variado que inclui turistas de todas as idades, moradores locais e grupos escolares, o Sarau Imperial oferece à plateia oportunidades de interação por meio da leitura de 
notícias da época, performances musicais e declamações no palco com o elenco, mas sobretudo a partir da expressão de preferências e opiniões pessoais. Nesse sentido, os participantes são convidados a descreverem sobre seus estilos musicais e esportes favoritos, bem como suas opiniões sobre assuntos como o machismo (a partir de uma canção e de um jornal do século XIX) e o abolicionismo, pauta do movimento que daria origem à libertação dos escravos no Brasil. Jogos de luzes utilizadas na ambientação da apresentação ajudam a provocar a plateia, focando-a em diversos momentos como forma de convidá-la a participar da encenação.

Nesse contexto, o Sarau Imperial se apresenta como arena de representações culturais e sociais em que se destaca a presença feminina, seja em virtude dos personagens e do elenco serem compostos integralmente por mulheres, seja pelo teor dos assuntos por elas discutidos durante a encenação.

No intuito de compreender as formas de representação do feminino e as práticas de turismo criativo durante o Sarau, realizamos uma pesquisa de caráter qualitativo, adotando-se como procedimentos de coleta de dados a observação participante, a análise de registros audiovisuais da dramatização e a consulta aos responsáveis pela produção. A fim de retratar a atração em momentos distintos, assistimos a três apresentações durante o mês de novembro de 2016, nas quais participamos como observadores participantes, realizando anotações e interagindo como o restante do público. Nas três ocasiões fizemos registros de foto e vídeo, com autorização da produção do Sarau. Os produtores nos auxiliaram ainda no fornecimento de informações técnicas sobre a concepção e o trabalho de pesquisa para a elaboração e a revisão do roteiro da dramatização.

Os dados coletados possibilitaram a organização de categorias de análise de aspectos significativos do Sarau, com foco nas representações femininas e nas práticas de turismo criativo nele retratadas. Nossas análises são apresentadas nas seções a seguir.

\section{IDENTIDADES FEMININAS DO SÉCULO XIX: REPRESENTAÇÕES E CHOQUES CULTURAIS NO SARAU IMPERIAL}

Em parte devido à presença de um elenco formado somente por mulheres, durante todo o Sarau são feitas alusões a elementos que remetem ao imaginário feminino da época. Vestuário, obrigações sociais das mulheres solteiras e casadas e hábitos culturais são colocados em pauta em situações que permitem a comparação espontânea, por parte da plateia, entre os códigos de comportamento do século XIX e os atuais. Em geral as reações são de surpresa, indignação ou de divertimento face ao estranhamento causado pelos 
diferentes papeis sociais a que o Sarau faz referências, principalmente no que diz respeito às mulheres, refletindo as formulações de Richards e Wilson (2006) e Richards (2010) de que a criação de atmosfera vibrante traz o envolvimento do público com a atração turística cultural de modo mais envolvente e único.

Logo no início da encenação ocorre o primeiro momento de interação com a plateia, quando as personagens comentam sobre passeios que realizaram recentemente e a Condessa de Barral pergunta a uma das mulheres presentes sobre que tipo de passeio ela aprecia. Nesse momento surgem alusões que auxiliam o público a identificar os costumes da época, como visitas pessoais, idas ao teatro e a concertos musicais. Nessa e em outras ocasiões fica claro que os lazeres experimentados pelas mulheres representadas no Sarau são compartilhados ou entre elas próprias ou com seus cônjuges - a exemplo do que Octobre (2011) observa em seus estudos sobre as trajetórias culturais de homens e mulheres a partir das práticas de lazer atribuídas a cada gênero. Nesse sentido, durante alguns momentos de interação com a plateia, as personagens manifestam estranhamento em relação às mulheres solteiras acompanhadas de seus namorados, o que não é considerado adequado nos códigos culturais da elite brasileira oitocentista.

Em outro momento de estranhamento entre os diferentes contextos culturais em que se encontram a plateia e as personagens, apresenta-se a canção "Conselhos", contendo orientações "para as senhorinhas que pretendem se casar e para as senhoras já casadas também", segundo a fala da personagem Adelaide Taunay. A letra da música de Carlos Gomes anuncia seu teor nos primeiros versos: "Menina, venha cá, deixe o que faz/ se por seu gosto o casamento quer/ a vontade ao marido irá fazer/ que este dever o casamento traz". Ao final da canção, a personagem Adelaide destaca a expressão assustada das mulheres na plateia, mas ressalta que os conselhos são pertinentes e que se comporta de modo submisso ao marido - ao que é exaltada pelas outras personagens do Sarau.

A indumentária das mulheres presentes na plateia também serve como mote para destacar diferenças em relação às personagens. Em algumas interações a plateia é questionada sobre o uso de "blue jeans" (cujo uso havia sido adotado recentemente entre trabalhadores de fazendas nos Estados Unidos) ou sobre a falta de saias ou vestimentas mais adequadas, por exemplo. Fotos de modelos de uma coleção europeia de vestidos da época são mostradas ao público, a fim de retratar a forma considerada correta e elegante para os trajes femininos.

A estranheza provocada nessas situações está relacionada tanto às diferenças de costumes sociais entre as mulheres como também à imposição de elementos que conferem a elas o status de "senhora" (termo utilizado nas referências às mulheres casadas) ou de 
"senhorinha" (usado para se referir às mulheres solteiras). Percebe-se, nesse sentido, a existência de um imaginário unificador da identidade feminina entre as mulheres do período do Segundo Reinado no Brasil, que se contrapõe às reflexões contemporâneas sobre gênero de autoras como Butler (1999) e Rago (1998), que cada vez mais apontam para a diversidade identitária e para a necessidade de considerarmos a multiplicidade de elementos que influenciam a condição feminina na sociedade.

Ao apresentar um momento de convívio social da Princesa Isabel com suas amigas, o Sarau Imperial permite observar o modo como sua educação se deu nos moldes daquilo que D. Pedro II julgava conveniente para uma mulher na sua posição, de acordo com Filgueiras (2004). Nesse sentido, por mais que a Princesa se ocupasse de funções públicas (sendo citada pela personagem da Condessa de Barral como regente), no meio social suas atenções se voltavam para a poesia e a música, interesses adequados para as mulheres em sua época.

Se, por um lado, os hábitos da época causam estranheza por parecerem ultrapassados, durante a encenação a plateia é constantemente convidada e provocada a se posicionar, sendo chamada a refletir sobre suas preferências e posições sociais nos tempos atuais. Opinando sobre seus passeios prediletos, esportes e músicas o público atua como mais um personagem da dramatização, apropriando-se de determinados momentos do Sarau e conferindo a ele um caráter flexível de criação espontânea e coletiva. Nesse sentido, a partir dos códigos culturais da elite oitocentista, as personagens lançam provocações sobre nossas próprias regras de conduta, levando-nos ao questionamento de posições preconceituosas presentes nas letras de canções e de notícias de jornal que se referem às mulheres. Levando em conta as formulações de Richards e Wilson (2006) sobre o turismo criativo, o Sarau Imperial se mostra como uma profícua plataforma de criação participativa em que o público de cada dia faz com que o espetáculo seja diferente a cada encenação. Dessa forma, segundo os produtores, há ocasiões em que a plateia manifesta revolta contra a cultura machista do século XIX, bem como participantes que reagem de forma exaltada com expressões como “Isso é um absurdo!” e “Essa música é um afronte!”.

Assumindo-se como parte do Sarau (ou como "convidados da Princesa Isabel”, na forma como se referem ao público as amigas da Princesa), a plateia confere à atração sentidos, interpretações e significados construídos a partir da interação com as personagens e com outros participantes. A encenação abre perspectivas para entendimentos diversos e cambiantes sobre as práticas sociais e as rotinas da Corte durante o Segundo Império. 


\section{A LEITURA DO JORNAL E A INTERAÇÃO DO PÚBLICO: GÊNEROS, CRIATIVIDADE E CONSUMO CULTURAL}

Parte do cotidiano do Imperador D. Pedro II e da própria Princesa Isabel envolvia a atualização das informações veiculadas em jornais da época, que eram lidos por conselheiros próximos à Casa Imperial, destacando para a monarquia brasileira somente as matérias que fossem representativas para sua leitura e compreensão dos acontecimentos.

Durante o Sarau Imperial este cotidiano é rememorado a partir da fala na qual a personagem que interpreta a Princesa Isabel apresenta sua visão como regente temporária do Brasil, pois D. Pedro II está em viagem externa, deixando o Império sob seu comando; a Princesa se queixa do peso que é conduzir a política intrincada e afirma que a leitura dos jornais é um pesadelo. Convém destacar que esta é a única ocasião em que se faz referência ao engajamento político da Princesa Isabel, numa sutil alusão ao movimento abolicionista.

Nesse momento do Sarau, os textos das atrizes que interpretam a Condessa de Barral e a própria Princesa Isabel apresentam uma visão masculina sobre como se construíam os papeis sociais de homens e mulheres durante o Segundo Império: elas chamam na plateia um cavalheiro para que faça a leitura de um artigo da seção "Avisos Importantes" de um jornal fac-símile intitulado "Gazeta de Notícias", de 17 de fevereiro de 1878 (Fotografia 2).

A participação do público masculino na leitura do texto deixa claro o estranhamento destes ao estarem na presença, mesmo que fíctícia, da Corte Imperial Brasileira: o comportamento dos leitores se faz sempre de forma comedida, formal e alguns buscam falar com a mesma linguagem empregada pelas personagens.

A criatividade neste ato se faz no emprego de um elemento que pode parecer simplório - a leitura de um texto. Contudo esta interação faz com que o público tome a participação ativa durante o Sarau, possibilitando àqueles que o leem e aos que assistem o consumo de forma educativa, e por que não dizer emocional, vivenciando o Sarau Imperial como apregoado por Richards e Wilson (2006; 2007), tal como por Cloke (2007) como turismo criativo: cada um daqueles que leem o texto passa a ter uma nova visão própria da atração cultural, não sendo possível reproduzir as mesmas experiências para todos.

O "Aviso Importante" lido durante a sessão traz um aconselhamento sobre como as senhoras da época deviam abanar seus maridos durante a noite para que os mosquitos não atrapalhassem o seu sono. O elenco se mostra atento aos "conselhos", mas ao final da leitura todas as personagens se mostram incomodadas com a visão machista do texto, pois o conselho se refere a uma representação do feminino como subserviente ao gênero masculino. 
O elenco diante a tal fato faz o questionamento ao leitor e ao público sobre o posicionamento machista do texto possibilitando, mesmo que anacronicamente, dado o período histórico no qual o Sarau é interpretado, a discussão da representação do feminino a partir da oposição das personagens à postura apresentada no trecho lido pelo convidado.

Convém destacar que nas três sessões em que participamos as atrizes sempre convidaram "um cavalheiro" - uma escolha prevista no roteiro do espetáculo que, segundo os produtores, é intencionalmente orientada à provocação do posicionamento masculino. Nesse sentido, o elenco é orientado a convidar homens que estejam acompanhados de suas esposas ou namoradas, para que, ao final da leitura, eles sejam inquiridos sobre suas opiniões a respeito do trecho reproduzido no jornal. Além de causar a reflexão comparativa sobre os papeis de gênero no período oitocentista em relação ao século XXI, a leitura dos "Avisos Importantes" representa um aspecto fundamental das relações de poder e gênero. Trazendo um trecho de autoria masculina, lido por homens mas fazendo referência a tarefas que caberiam às mulheres durante o período retratado, a cena corrobora as formulações de Bozon (2003), Bordieu (2012) e Lana e Leal (2014), a partir das quais nossos modos de pensar e compreender o mundo muitas vezes partem de elaborações androcêntricas, já naturalizadas cultural e socialmente.

O Sarau ainda possui uma segunda interação do público com a leitura do jornal, mas nesta segunda interação as atrizes solicitam em duas sessões por "senhoras" ou "senhorinhas", pois a seção é um poema intitulado "Uma cantora", uma leitura mais apropriada para o gênero feminino à época na qual a peça é encenada; em uma outra sessão a leitura é feita por um "cavalheiro".

A leitura do poema traz ao palco novamente o público como elemento principal da construção da narrativa da peça, não sendo esta uma atração passiva, na qual o texto é encenado e o público em silêncio o assiste; pelo contrário, nestes momentos o elenco do Sarau Imperial dialoga com o público, possibilitando a vivência dos aspectos socioculturais da elite brasileira oitocentista, não mais como sujeito passivo e isolado por cordões de segurança.

Os padrões socioculturais do período do Segundo Império e, por conseguinte, da própria Corte, tornam-se elementos vivos, possibilitando à platéia do Sarau Imperial o contato de forma única com a cultura, corroborando o pensamento de que o turismo criativo é aquele que traz à tona novas práticas e posturas perante a história, a memória e as tradições locais (Richards, 2010).

As leituras do "Aviso Importante" e do poema trazem à tona a complexa representação do feminino que foi sendo construída ao longo dos anos no Brasil e no mundo, 
cujos padrões binários são questionados por autoras como Octobre (2011) e Buscatto (2014), seja na esfera das experiências culturais e de lazer ou nas outras formas de convivência social.

\section{CONSIDERAÇÕES FINAIS}

O desenvolvimento de atrações turísticas criativas se estabelece no âmago dos bens culturais próprios de uma destinação turística, quebrando a lógica da necessidade da (re)produção de novos atrativos/atrações para que haja a continuidade da visitação turística por parte de turistas e visitantes.

O turismo criativo precisa que a destinação valorize seus bens culturais materiais e imateriais, para que então possa desenvolver novas e inovadoras formas de ofertar mais do que simplesmente atrações passivas, isto é, atrações que geram nos turistas e visitantes sentimentos e emoções que se podem encontrar/vivenciar em outras destinações de semelhança atrativa.

A inovação e a criatividade turística, quando vistas sob a ótica da produção de novos sentidos para os bens culturais, fazem com que a destinação passe a ofertar mais valor, experiência e emoções aos turistas e visitantes, propiciando uma nova forma de interação com a atmosfera turística local criada a partir de suas peculiaridades.

No Sarau Imperial, objeto deste estudo, as representações e os imaginários femininos da elite brasileira oitocentista, em especial aqueles que se referem à história da vida privada da Princesa Isabel e suas amigas são recriados por meio da dramatização participativa, propiciando à platéia uma série de contatos e aprendizagens com o universo cultural dos bens históricos guardados pelo Museu Imperial de Petrópolis.

As relações de identidade de gênero, com foco na representação do feminino, tornam o Sarau Imperial uma atração singular sob os aspectos investigados neste estudo, possibilitando a discussão da temática a partir das articulações entre a ótica da platéia participante com a do elenco representando o dualismo de tempos, costumes e comportamentos. Ao final de cada apresentação a percepção do público se divide entre a sensação de entretenimento e, por outro lado, de reflexão sobre as diferenças da condição feminina atual e daquela retratada durante o Sarau. O espetáculo se propõe como plataforma de múltiplas possibilidades de interpretação do feminino a partir de situações que, à luz das práticas sociais contemporâneas, podem ser consideradas machistas ou obsoletas. Da mesma forma, somos provocados a analisar em que medida avançamos ou não no questionamento sobre as relações e os papeis de gênero socialmente determinados. 
O que se pode perceber é que o Museu Imperial de Petrópolis, a partir da introdução de um espetáculo participativo, pôde suscitar a discussão do cotidiano oitocentista brasileiro, sem que houvesse uma mudança de aspecto físico-estrutural em sua coleção de objetos e obras de arte já apresentadas ao público, demonstrando que o turismo criativo pode ser uma nova forma de concepção de planejamento tanto para o atrativo turístico cultural em si, quanto para as destinações turísticas histórico-culturais.

Não se pode argumentar que o Sarau Imperial busca esgotar a temática da representação do feminino, de identidade de gênero e outras representações que se construíram ao longo dos anos no imaginário sociocultural brasileiro; pelo contrário, a encenação é apenas uma visão parcial destas discussões e de como o Museu Imperial pode ser ainda mais utilizado para que novos olhares, pesquisas e produções culturais criativas possam inserir nas agendas locais atrações turísticas que possibilitem a turistas, visitantes e moradores locais o entendimento de como as discussões e representações de gênero foram relevantes para a construção do atual imaginário brasileiro.

O Sarau Imperial e, por conseguinte, o próprio Museu Imperial, carecem de mais estudos e pesquisas que se aprofundem na compreensão de como o conteúdo histórico, biográfico e sociocultural sobre os membros da Família Imperial Brasileira do Segundo Reinado podem contribuir para a inovação na atividade turística e mesmo para o entendimento das representações do feminino no Brasil.

\section{REFERÊNCIAS}

Barman, R. J. (2005). Princesa Isabel do Brasil: gênero e poder no século XIX. São Paulo: Unesp.

Bourdieu, P. (2007). A distinção: crítica social do julgamento. São Paulo: Edusp; Porto Alegre: Zulk.

. (2012). A dominação masculina. (11a ed.). Rio de Janeiro: Bertrand Brasil.

Bozon, M. (2003). Sexualidade e conjugalidade: a redefinição das relações de gênero na França contemporânea. Cadernos Pagu, n. 20, p. 131-156.

Buscatto, Marie. (2014). La culture, c'est (aussi) une question de genre. In: Octobre, Sylvie. Questions de genre, questions de culture. Paris: Ministére de la Culture et de la Communication - DEPS, 125-143.

Butler, Judith. (1999). Gender Trouble. New York: Routledge Press.

Cloke, P. (2007). Creativity and tourism in rural environments. In: Richards, G.; Wilson, J. (org). Tourism, creativity and development. Oxon: Routledge, 37- 47. 
Cruz, R. de O. (2012). Nas "batalhas de flores" não faltavam espinhos: Silva Jardim e a Pincesa Isabel no cenário politico do final da monarquia brasileira (1886-1889). Historien Revista de História, 4, 41-63. Petrolina.

Daibert Júnior, R. (2003). Gênero e política: um olhar (estrangeiro) sobre a Princesa Isabel. Estudos Feministas, 11(2), 661-680. Florianópolis.

Filgueiras, C. A. L. (2004). A Química na educação da Princesa Isabel. Química Nova, 27(2), 349-355.

Funari, P. P. \& Pinsky, J. (org.) (2011). Turismo e patrimônio cultural. São Paulo: Contexto.

Geertz, C. (1989). A interpretação das culturas. Rio de Janeiro: Guanabara.

Lana, L. \& Leal, T. (2014). Sucesso, feminilidade e negócios: representações jornalísticas das "mulheres poderosas". Líbero, 17(33), 95-104. São Paulo.

Le Goff, J. (1990). História e memória. Trad. Bernardo Leitão. Campinas: Editora da UNICAMP.

Molina, S. (2003). O pós-turismo. Trad. Roberto Sperling. São Paulo: Aleph.

Museu Imperial (2016). Recuperado em 30 de novembro, 2016, de http://www.museuimperial.gov.br/eventos/espetaculos/sarau-imperial.html.

Octobre, S. (2011). Du féminin et du masculin. Genre et trajectoires culturelles. Réseaux, (168-169), 23-57.

(2014). Réflexions liminaires sur le genre et les pratiques culturelles: féminisation, socialisation et domination. In: Questions de genre, questions de culture. Paris: Ministére de la Culture et de la Communication, - DEPS, 7-25.

Rago, M. (1995). As mulheres na historiografia brasileira. In: Silva, Zélia L. (org.). Cultura histórica em debate, 81-91. São Paulo: Unesp. . (1998). Descobrindo historicamente o gênero. Cadernos Pagu, (11), 89-98.

Rejowski, M., Yasohima, J. R., Stigliano, B. V. \& Silveira, A. S. (2002) Desenvolvimento do turismo. In Rejowski, M. (org.). Turismo no percurso do tempo. São Paulo: Aleph, p. 43-74.

Richards, G; Raymond, C. (2000). Creative Tourism. ATLAS News, (23), 16-20.

Richards, G., (2010). Tourism development trajectories - from culture to creativity?. Econtros cientificos - tourism \& management studies, (6), 9-15.

Richards, G. \& Wilson, J. (2007). Tourism development trajectories: from culture to creativity? In: Richards, G.; Wilson, J. (org). Tourism, creativity and development, 1-33. Oxon: Routledge.

. (2006). Developing creativity in tourist experiences: a solution to the serial reproduction of culture?. Tourism management, 27, 1209-1223. 
Scott, J. (1986). Gender: a useful category of historical analyses. The American Historical Review, 91(5), 1053-1075.

Schwarcz, L. M. (1998). As barbas do imperador: D. Pedro II, um monarca nos trópicos. São Paulo: Companhia das Letras.

UNESCO. (2013). Creative Cities Network. Recuperado em 05 de novembro, 2016, de http://en.unesco.org/creative-cities/home.

Urry, J. (1996). O olhar do turista: lazer e viagens nas sociedades contemporâneas. São Paulo: Studio Nobel: SESC.

Yasohima, J. R. \& Oliveira, N. S. (2002). Antecedentes das viagens e do turismo. In: Rejowski, M. (org.). Turismo no percurso do tempo, 17-41. São Paulo: Aleph.

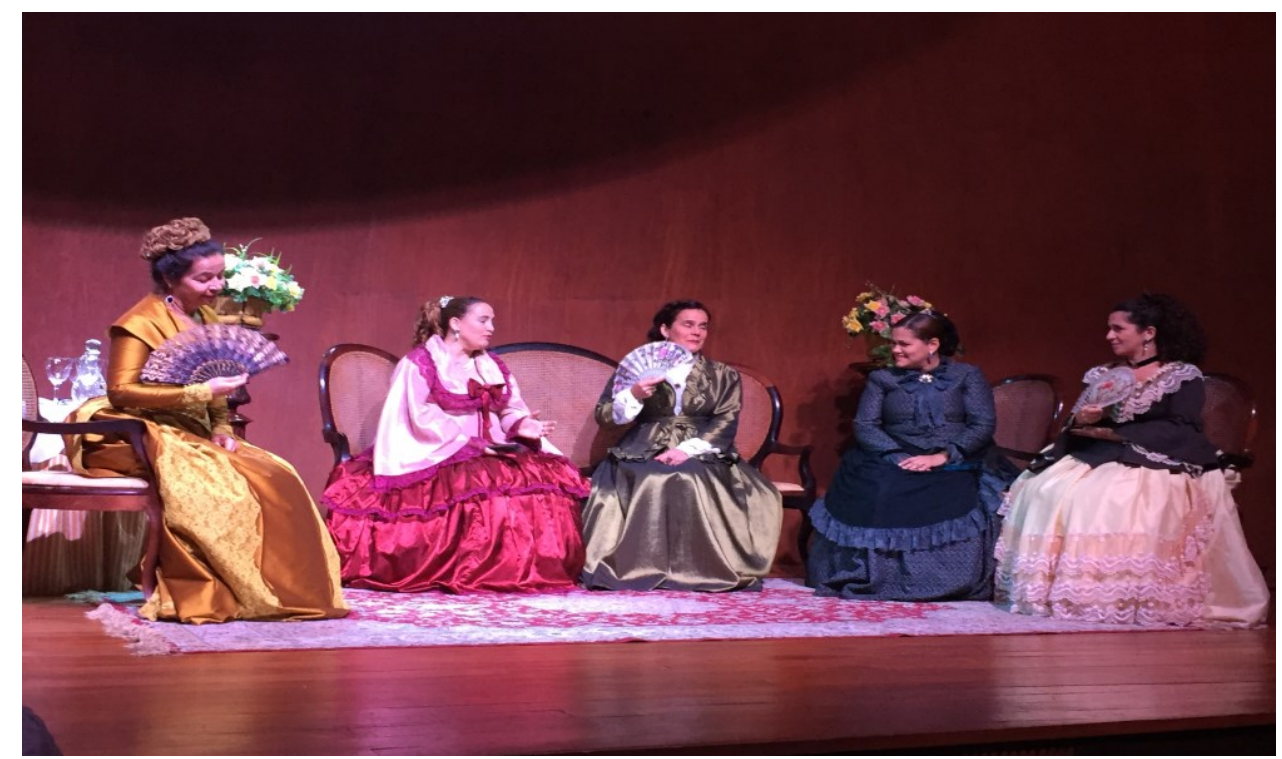

Fotografia 1 - Elenco do Sarau Imperial Fonte: Arquivo pessoal

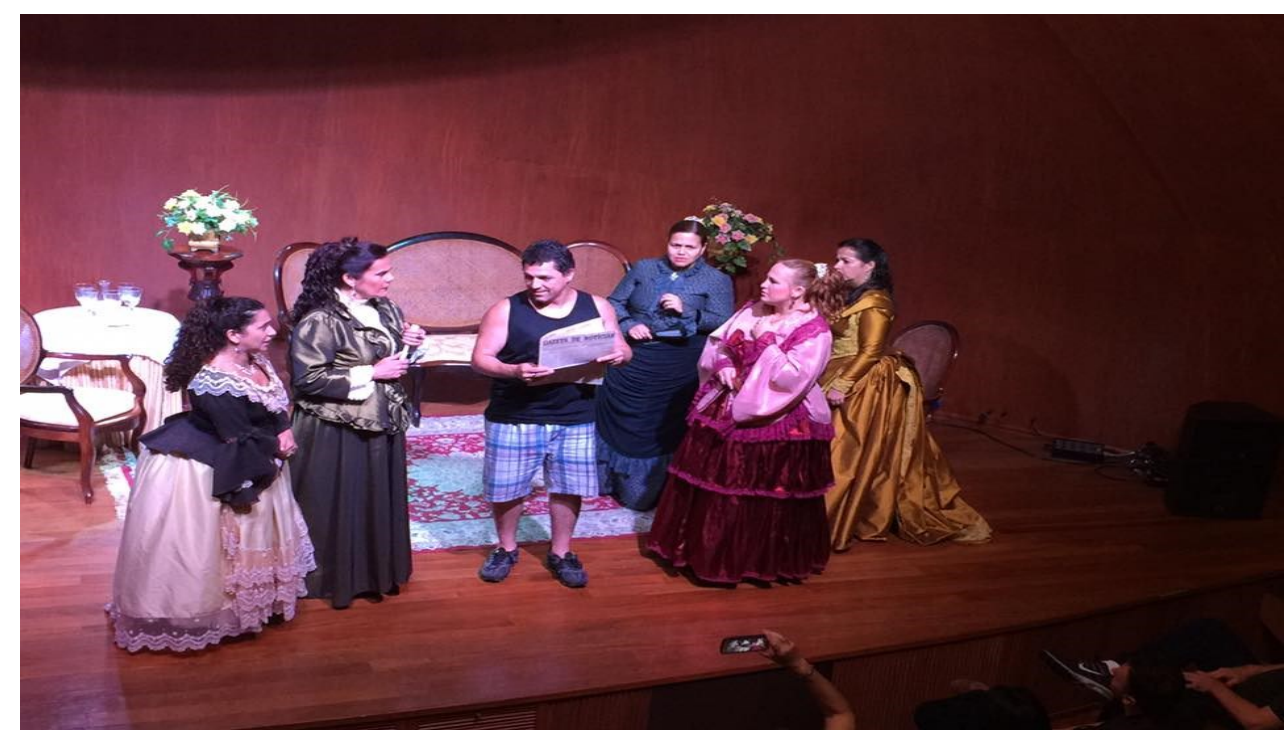

Fotografia 2 - Leitura dos "Avisos Importantes"

Fonte: Página do Sarau Imperial na rede social Facebook 